\title{
ESCHERICHIA COLI E SEU IMPACTO NA SAÚDE PÚBLICA
}

Fabíola de Azevedo Mello, Letícia Aparecida Costa

Universidade do Oeste Paulista - UNOESTE, Mestrado em Meio ambiente e Desenvolvimento Regional, Presidente Prudente, SP. E-mail: fabiola-azevedo@hotmail.com

\section{RESUMO}

A água é de extrema importância para a sobrevivência dos seres vivos existentes no planeta, e atualmente um grave problema ambiental é a sua contaminação. A potabilidade da água muitas vezes não é perceptível, fazendo-se necessárias análises laboratoriais para detectá-la. O objetivo desse estudo foi verificar quais são as consequências que a bactéria Escherichia coli pode provocar nos seres humanos que consomem água contaminada e quais são os padrões da água potável. A metodologia utilizada foi por meio de pesquisas bibliográficas e documentais. Com os resultados foi possível verificar quais problemas a água contaminada pode ocasionar na saúde humana e quais são os padrões de potabilidade que devem ser respeitados. Concluímos que as análises microbiológicas da água são de grande importância para garantir qualidade de vida à população, visto que a bactéria $E$. coli pode provocar diversos danos a saúde humana.

Palavras-chave: Escherichia coli, potalibidade da água, contaminação, saúde.

\section{ESCHERICHIA COLI AND ITS IMPACT ON PUBLIC HEALTH}

\begin{abstract}
Water is extremely important for the survival of living beings existing on the planet, and now a serious environmental problem is the contamination. Water potability The often not noticeable, making it necessary laboratory tests to detect it. The aim of this study was to determine what are the consequences of the Escherichia coli bacteria can cause in humans who consume contaminated water and what are the standards of drinking water. The methodology used was through bibliographic and documentary research. The results made it possible to see what problems the contaminated water can cause human health and what are the potability standards that must be respected. We concluded that the microbiological water analyzes are of great importance to ensure the population quality of life, since the E. coli bacteria can cause extensive damage to human health.
\end{abstract}

Keywords: Escherichia coli, potalibidade water, contamination, health. 


\section{INTRODUÇÃO}

A água é de extrema importância para a sobrevivência dos seres vivos existentes no planeta, pois se faz presente em quase todos os processos biológicos, além de ocupar aproximadamente três quartos de toda a superfície terrestre (BENEDETTI, 2013).

Atualmente um problema corriqueiro é a contaminação de organismos naturais de água, principalmente em países em desenvolvimento, pois os resíduos domésticos e industriais são dispostos nos ecossistemas aquáticos com tratamento inadequado, ineficiente ou até sem nenhum tipo de tratamento (ROMEU-ALVAREZ, 2013).

Para se determinar a qualidade microbiológica dos ecossistemas aquáticos são realizadas análises das bactérias indicadoras de contaminação fecal. As mais utilizadas são os coliformes totais e termotolerantes, embora a Escherichia coli apresente uma associação maior quando comparado com os outros parâmetros em relação à saúde humana (ROMEU-ALVAREZ, 2013).

\section{Qualidade da água}

A qualidade da água tornou-se uma questão de grande interesse para a saúde pública entre os séculos XIX e XX, já que antes associava-se apenas aos aspectos sensoriais e estéticos como, por exemplo, odor, cor e gosto (SANTOS, 2014).

De acordo com Souza (2013) 80\% das internações hospitalares, no Brasil, são ocasionadas por doenças de veiculação hídrica, ou seja, são doenças provenientes da má qualidade da água para o consumo da população.

A água destinada ao abastecimento humano é considerada potável quando seus valores permissíveis estão de acordo com os parâmetros físicos, químicos, microbiológicos e organolépticos. De acordo com a Portaria $n^{\circ} 1469$ de 29 de dezembro de 2000, do Ministério da Saúde, a água é considerada potável quando não oferece riscos à saúde dos seres humanos e obedece os padrões de potabilidade (SANTOS, 2014).

Os parâmetros físico-químicos principais de qualidade da águas são: turbidez, cor, temperatura, sabor, $\mathrm{pH}$, alcalinidade, fósforo, fluoretos, dureza, manganês, nitrogênio, oxigênio dissolvido, matéria orgânica, além de poluentes orgânicos e inorgânicos (SOUZA, 2014).

\section{Poluição hídrica}

O modo de vida do ser humano e o crescimento populacional geraram diversos impactos ao meio ambiente. $O$ homem altera as diversas paisagens através da urbanização, agricultura, indústrias, além da criação de animais. A água e o solo, por sua vez, tornam-se poluídos, aumentando a destruição das áreas naturais, explorando os recursos naturais, levando a extinção de diversas espécies.

Desde os tempos remotos, a água vem provocando inúmeras epidemias e continua sendo responsável por catástrofes nos países pobres. Com o surgimento da agricultura há 10 mil anos, os seres humanos se alocaram nas margens férteis dos lagos e rios, e suas bactérias intestinais acabavam ficando nesses locais também, se diferenciando do hábito nômade que precedeu a agricultura. A partir de então, as bactérias eram excretadas nessas regiões, que se tornariam as primeiras grandes civilizações humanas. Os riachos, rios e lagos recebiam as fezes humanas e calhavam a transmitir aos recém-nascidos algumas epidemias, a partir de então, o homem começou a conhecer as epidemias diarreicas decorrentes da própria alteração do meio ambiente (UJVARI, 2004).

De acordo com UJVARI, p. 69:

$\mathrm{O}$ aumento urbano mundial desorganizado foi acompanhado de sistemas de esgoto ineficazes e de nenhum abastecimento de água, justamente quando era maior a eliminação de excrementos na natureza. Hoje, quase metade da população mundial não dispõe de sistemas de saneamento 
básico, e mais de um sexto dela bebe água imprópria à saúde (UJVARI, 2004).

\section{Escherichia coli $x$ saúde humana}

As principais bactérias pertencenter ao grupo dos coliformes totais são as do gênero Escherichia, Citrobacter, Enterobacter e Klebsiella. Faz parte desse grupo os bacilos Gramnegativos não esporulados e que pertencem a família Enterobacteriacea, além de não fermentarem a lactose e produzirem gás quando incubados $\left(37^{\circ} \mathrm{C}\right.$ por $24-48$ horas). A bactéria Escherichia coli faz parte do grupo dos coliformes termotolerantes, que são os coliformes totais, pois continuam fermentando a lactose e produzindo gás $\left(44-45^{\circ} \mathrm{C}\right.$ em 24 horas). Além do mais, essa bactéria é utilizada para indicar se houve contaminação fecal na água, já que é um microrganismo presente na microbiota intestinal dos animais (MULLER, 2014).

A associação entre água contaminada e à falta de saneamento básico causa uma mortalidade anual de cerca de 1,6 milhões de pessoas no mundo. Nem sempre a ausência da potabilidade da água é perceptível à visão ou olfato, tornando-se necessária uma análise laboratorial para detectá-la. O controle microbiológico da água, devido a sua característica de veículo de transmissão de bactérias, se torna imprescindível analisar coliformes totais e termotolerantes, protozoários, vírus e fungos causadores de diversas doenças ao homem. Esses microrganismos são responsáveis pela ocorrência de doenças de veiculação hídrica como: diarreias, disenterias, hepatites, cólera, entre outras enfermidades graves (YAMAGUCHI, 2013).

A via de transmissão dos microrganismos para o organismo humano é realizado por via cutânea ou por ingestão de água contaminada; por contato primário com águas de recreação e ainda por ingestão de líquidos ou alimentos contaminados que podem ser infectados durante o preparo ou no ambiente de origem. Podem ser encontrado nos esgotos mais de 100 organismos patogênicos entéricos, como vírus, parasitas e bactérias (YAMAGUCHI, 2013).

As bactérias indicadoras de contaminação fecal e os microrganismo patogênicos não devem estar presentes na água potável. O grupo de bactérias denominadas coliformes é tradicionalmente aceitos como indicadores de contaminação fecal, e o principal representante desse grupo é a bactéria Escherichia coli (BRASIL, 2006).

A Portaria no 2914 de 12 de dezembro de 2011 do Ministério da Saúde, que alterou a Portaria 518/2004, dispõe sobre os procedimentos de controle e de vigilância da qualidade da água para consumo humano e seu padrão de potabilidade, no artigo 27 determina que a água potável deve estar em conformidade com o padrão microbiológico, e no anexo I é disposto que a Escherichia coli deve ser ausente em $100 \mathrm{~mL}$ (BRASIL, 2011).

O objetivo deste estudo foi verificar quais são as consequências que a bactéria Escherichia coli pode provocar nos seres humanos que consomem água contaminada e quais são os padrões vigentes em lei que determinam quais microrganismos não devem estar presentes na água potável.

\section{METODOLOGIA}

O caminho metodológico utilizado nesse trabalho foi por meio de pesquisas bibliográficas e documentais sobre a importância da bactéria Escherichia coli, as formas de transmissão, o impacto no meio ambiente, os problemas ocasionados à saúde humana, e as determinações sobre os padrões de consumo de água contaminada com a bactéria em estudo.

No delineamento desse trabalho, foram considerados diversos estudos que analisaram os problemas decorrentes da Escherichia coli na água para consumo humano e seus impactos na saúde. 


\section{RESULTADOS}

As bactérias desenvolvem funções importantes aos seres humanos, especialmente na produção de antibióticos e na composição da microbiota natural, no entanto, algumas espécies podem ser patogênicas (SILVA; KELLER; RODRIGUES, 2015).

A Escherichia coli, também denominada de E.coli, é uma bactéria que vive comumente dentro do intestino dos mamíferos, pois oferecem uma vasta quantidade de nutrientes para o crescimento bacteriano. São eliminados todos os dias trilhões de bactérias do tipo E. coli. As doenças provocadas por ela acontecem quando a bactéria consegue alcançar outros órgãos do nosso corpo, como exemplo, a bexiga. Devido à proximidade da uretra feminina com o ânus, frequentemente, a Escherichia coli consegue passar do trato digestivo para o trato urinário ocasionando a maioria das infecções urinárias (PINHEIRO, 2016).

A infecção mais comum ocasionada por ela é a infecção urinária, todavia, esta bactéria também pode causar várias outras infecções como abscesso no fígado, pneumonia, meningite, artrite, colecistite (infecção da vesícula), etc. A contaminação através de alimentos também é comum e se dá por vegetais regados ou lavados com água contaminada, alimentos crus, mal cozidos ou preparados por cozinheiros ou açougueiros que não lavam as mãos adequadamente após evacuarem. A carne também pode se contaminar no momento do abate, ainda antes de chegar ao açougue ou supermercado (PINHEIRO, 2016).

Com o aumento do consumo da água para diversos fins e crescimento da população em todo o mundo tem contribuído para o aumento dos níveis de contaminação dos sistemas aquáticos. O controle e qualidade microbiológica da água potável e eliminação dos possíveis contaminantes requer uma análises que seja capaz de determinar a presença de patógenos (MURRELL, 2013).

A alternativa para um controle de qualidade confiável, econômico e rápido é realizar análises microbiológicas da água, para tal a utilização de indicadores de contaminação fecais mais utilizados são os coliformes totais e termotolerantes, Escherichia coli e enterococos (MURRELL, 2013).

De acordo com a Portaria 2.914 de 12 de dezembro de 2011 que dispõe sobre os procedimentos de controle e de vigilância da qualidade da água para consumo humano e seu padrão de potabilidade em seu artigo 3o "Toda água destinada ao consumo humano, distribuída coletivamente por meio de sistema ou solução alternativa coletiva de abastecimento de água, deve ser objeto de controle e vigilância da qualidade da água". A água potável deve atender aos padrões de potabilidade estabelecidos na Portaria, não oferecendo riscos à saúde.

No item da Portaria que trata dos padrões de potabilidade, no artigo 27 é descrito que a água potável deve estar em conformidade com padrão microbiológico, e nos parágrafos desse artigo:

$\S 1$ 을 No controle da qualidade da água, quando forem detectadas amostras com resultado positivo para coliformes totais, mesmo em ensaios presuntivos, ações corretivas devem ser adotadas e novas amostras devem ser coletadas em dias imediatamente sucessivos até que revelem resultados satisfatórios.

$\S 2$ ㅇ Nos sistemas de distribuição, as novas amostras devem incluir no mínimo uma recoleta no ponto onde foi constatado o resultado positivo para coliformes totais e duas amostras extras, sendo uma à montante e outra à jusante do local da recoleta.

$\S$ 3ㅇ Para verificação do percentual mensal das amostras com resultados positivos de coliformes totais, as recoletas não devem ser consideradas no cálculo. 
$\S 4$ O O resultado negativo para coliformes totais das recoletas não anula o resultado originalmente positivo no cálculo dos percentuais de amostras com resultado positivo.

No anexo da Portaria, é descrito os padrões microbiológicos da água para consumo humano, como se pode observar na tabela abaixo:

Tabela 1. Padrão microbiológico da água para consumo humano

\begin{tabular}{|l|l|}
\hline \multicolumn{2}{|c|}{ Tipo de ágüa } \\
\hline \multicolumn{2}{|c|}{ Água para consumo humano } \\
\hline & Na saida do tratamento \\
\hline & No sistema de distribuiç̧̃o (reservatórios e rede) \\
& \\
\hline
\end{tabular}

NOTAS: (1) Valor máximo permitido.

(2) Indicador de contaminação fecal.

(3) Indicador de eficiência de tratamento.

(4) Indicador de integridade do sistema de distribuição (reservatório e rede).

\begin{tabular}{|c|c|c|}
\hline \multicolumn{2}{|r|}{ Parâmetro } & \begin{tabular}{|r|} 
VMP(1) $^{(1)}$ \\
\end{tabular} \\
\hline & Escherichia $\operatorname{col}^{(2)}$ & Ausência $\mathrm{em} 100 \mathrm{~mL}$ \\
\hline Coliformes totais (3) & & Ausência em $100 \mathrm{~mL}$ \\
\hline Escherichia coli & & Ausência $\mathrm{em} 100 \mathrm{~mL}$ \\
\hline \multirow[t]{2}{*}{ Coliformes totais ${ }^{(4)}$} & $\begin{array}{l}\text { Sistemas ou soluções alternativas coletivas que abastecem menos } \\
\text { de } 20.000 \text { habitantes }\end{array}$ & $\begin{array}{l}\text { Apenas uma amostra, entre as amostras examinadas no mês, poderá } \\
\text { apresentar resultado positivo }\end{array}$ \\
\hline & $\begin{array}{l}\text { Sistemas ou soluçōes alternativas coletivas que abastecem a partir } \\
\text { de } 20.000 \text { habitantes }\end{array}$ & Ausência em $100 \mathrm{~mL}$ em $95 \%$ das amostras examinadas no mês. \\
\hline
\end{tabular}

Fonte: Portaria 2.914/2011 do Ministério da Saúde (BRASIL, 2011).

\section{DISCUSSÃO}

A água potável que é destinada para o consumo humano deve obedecer alguns parâmetros para que não afete a saúde humana e promova benefícios. Os fatores levantados no trabalho evidenciam que organismos patogênicos e algumas bactérias são ótimos indicadores de contaminação, por tanto, devem ser analisados frequentemente para garantir a qualidade da água.

O grupo escolhido para ser discutido nesse trabalho foi a Escherichia coli, os motivos que justificam a escolha desse grupo de bactérias como indicador de contaminação da água é que estão presentes nas fezes de animais de sangue quente, inclusive os seres humanos; sua presença na água possui uma relação direta com o grau de contaminação fecal; são detectáveis prontamente e quantificáveis por técnicas simples e financeiramente viáveis, em qualquer tipo de água; são mais resistentes na água que as bactérias patogênicas intestinais, por serem menos exigentes em termos nutricionais, além de ser incapazes de se multiplicarem no ambiente aquático; são mais resistentes à ação dos agentes desinfetantes do que os germes patogênicos (BRASIL, 2006).

De acordo com Santos (2014) há dois fatores relevantes que associam-se aos benefícios à saúde, que são a qualidade e quantidade da água, já que relacionam-se a incidência e prevalência de várias doenças, tendo destaque as doenças diarreicas. Ainda de acordo com o autor, 1,5 milhões e meio de crianças morrem por ano devido as doenças associadas a diarréia e 2 bilhões e meio de indivíduos acabam não tendo acesso ao saneamento básico. Por isso, é de extrema importância que além do acesso a água é preciso também garantir sua qualidade.

\section{CONSIDERAÇÕES FINAIS}

Os resultados obtidos no presente estudo levam a considerar que existe relação entre a água contaminada e os riscos a saúde da população, sendo um meio de transmissão de inúmeros 
agentes químicos e biológicos. Com o aumento indiscriminado do uso dos recursos naturais, sem grandes preocupações com a escassez, a contaminação ambiental tem se feito presente em diversos seguimentos e um deles é a água. Portanto, avaliar a qualidade da água é de extrema importância, pois garante a segurança de seu uso.

As bactérias e outros microrganismos podem impactar negativamente a saúde humana, por isso para se garantir a potabilidade da água devem ser respeitados rigorosamente os padrões estabelecidos na portaria vigente no país. Pode-se concluir que as análises laboratoriais nas águas para consumo humano são de extrema importância, para garantir sua qualidade e segurança na saúde.

\section{REFERÊNCIAS}

BENEDETTI, E. Água- Fonte da vida- Considerações. Veterinária Notícias, Uberlândia, v. 18, n. 1, p. 1-5, jan./jun. 2013.

BRASIL. Portaria n.o 2914, de 12 de dezembro de 2011. Dispõe sobre os procedimentos de controle e de vigilância da qualidade da água para consumo humano e seu padrão de potabilidade. Ministério da Saúde.

BRASIL. Manual prático de análise de água. Fundação Nacional de Saúde, Brasília, 2ª ed. rev. 2006.

MURRELL, L. M.; ADINA, J.; ALVAREZ, R.; BADIA, B. R.; MARIA, M. PEREZ, H.; HERNÁNDEZ, R.; MERCEDES, N.; Bacterias indicadoras de contaminación fecal en la evaluación de la calidad de las aguas: revisión de la literatura. Revista CENIC Ciencias Biológicas, Vol. 44, №. 3, pp. 24-34, 2013.

MULLER, L. R. PARUSSOLO, L. Qualidade microbiológica da água utilizada para consumo em escolas municipais de Mamborê, Paraná. SaBios-Revista de Saúde e Biologia, v. 9, n. 1, p. 95-99, jan./abr. 2014.

PINHEIRO, P. Diarreia pela bactéria Escherichia coli (E.COLI). Disponível em: < http://www.mdsaude.com/2011/06/bacteria-escherichia-coli.html>. Acesso em 02 ago. 2016

SANTOS, P. R. Aspectos epidemiológicos e microbiológicos na distribuição da água potável em comunidade de João Pessoa-PB. 2014. 38 f. Monografia (Bacharel em Farmácia). Universidade Federal da Paraíba, João Pessoa- PB.

SOUZA, S. S. Prevalência de enteroparasitoses e sua relação com a origem da água de consumo humano, na comunidade de Uruçu-São João do Cariri-PB. 2013. 31 f. Monografia (Bacharel e Licenciatura em Enfermagem). Universidade Estadual da Paraíba, Campina Grande-PB.

UJVARI, Stefan Cunha. Meio ambiente e epidemias. São Paulo: Editora Senac, 2004.

YAMAGUCHI, M. U.; CORTEZ, L. E. R.; OTTONI, L. C. C.; OYAMA, J. Qualidade microbiológica da água para consumo humano em instituição de ensino de Maringá-PR. Revista: $O$ mundo da saúde, São Paulo, v. 37, n. 3, p. 312-320, 2013. 